Check for updates

Cite this: RSC Adv., 2018, 8, 4713

Received 16th December 2017

Accepted 22nd January 2018

DOI: $10.1039 / c 7 r a 13382 k$

rsc.li/rsc-advances

\section{Pervaporation separation of ethyl acetate from aqueous solutions using ZSM-5 filled dual-layer poly(ether-block-amide)/polyethersulfone membrane}

\begin{abstract}
M. Vatani, A. Raisi $\mathbb{D}$ * and G. Pazuki
In the present study, dual-layer mixed matrix membranes (MMMs) were prepared by incorporating ZSM-5 zeolite into poly(ether-block-amide) (PEBA) as an active layer on the polyethersulfone (PES) membrane as a support layer for pervaporation separation of ethyl acetate (EAC) from EAc/water mixtures. The ZSM-5 zeolite nanoparticles were synthesized by the hydrothermal technique and characterized using XRD, XRF and FESEM analysis. The ATR-FTIR, SEM, DSC and contact angle tests were used to characterize the fabricated MMMs. The effect of ZSM-5 concentration on the performance of the membranes was investigated by the pervaporation experiments and the results showed that loading $10 \%$ wt $\%$ ZSM-5 into the PEBA matrix had the best separation performance. The effect of feed concentration (1-5 wt $\%$ ) and operating temperature $\left(30-50^{\circ} \mathrm{C}\right)$ on the separation factor and permeation flux of the neat PEBA/PES and PEBA/PES membranes containing $10 \mathrm{wt} \%$ ZSM-5 were studied at laminar and turbulent feed flow regimes. Analysis of variance was used to investigate the interaction effect of EAc concentration and temperature on the performance of the prepared membranes. It was observed that both feed concentration and temperature had positive effects on the total permeation flux and separation factor. The ZSM-5/PEBA/PES membrane containing 10 wt\% ZSM-5 showed a separation factor and total flux of 124.94 and $1882 \mathrm{~g} \mathrm{~m}^{-2} \mathrm{~h}^{-1}$ at laminar flow and 134.22 and $1985 \mathrm{~g} \mathrm{~m}^{-2} \mathrm{~h}^{-1}$ at turbulent flow, respectively for a feed concentration of $5 \mathrm{wt} \%$ and temperature of $50{ }^{\circ} \mathrm{C}$.
\end{abstract}

\section{Introduction}

Pervaporation, as a membrane separation technology, is an efficient method for the separation of organic compounds from aqueous solutions in comparison to conventional processes like distillation due to energy-saving process, low production costs and high selectivity. ${ }^{1}$ Three types of materials including polymers, inorganic and composite materials have been used for fabrication of the pervaporation membranes. ${ }^{2}$ The hydrophobic polymers were used to enhance the efficiency of polymeric membranes toward the separation of organic compounds with low concentrations from aqueous solutions.$^{3-5}$ However, the use of polymeric membranes due to the low chemical and thermal stability as well as intrinsic trade-off between permeability and selectivity is limited. ${ }^{6}$ The higher chemical and thermal stability were obtained by preparing inorganic membranes. ${ }^{7}$ However, the main drawback of inorganic membranes is the high brittleness and difficult fabrication of inorganic defect-free membranes in the large scale. ${ }^{8}$ Mixed matrix membranes

Department of Chemical Engineering, Amirkabir University of Technology (Tehran Polytechnic), Hafez Ave, P. O. Box 15875-4413, Tehran, Iran.E-mail: raisia@aut.ac. ir; Fax: +98 21 66405847; Tel: +982164543125
(MMMs) have been prepared from the polymeric and inorganic materials to overcome the drawbacks of neat polymeric and inorganic membranes. ${ }^{9}$ The MMMs were prepared via different methods such as physical blending of the polymer and inorganic materials, ${ }^{10}$ sol-gel method, ${ }^{11}$ in situ polymerization ${ }^{12}$ and self-assembly method. ${ }^{13}$ Among them, the physical blending of polymer/inorganic materials and sol-gel methods were commonly used for fabrication of the pervaporation MMMs. However, in the development of the MMMs, there are several challenges such as inorganic particles agglomeration and sedimentation, interfacial voids, low adhesion, polymer chains rigidification and pore blockage which have significant effects on the separation performance of the pervaporation membranes.

Various inorganic materials as filler including activated carbon, ${ }^{14}$ graphene oxide, ${ }^{15}$ carbon nanotubes, ${ }^{16}$ metal oxide nanoparticles, ${ }^{17}$ clay, ${ }^{18}$ mesoporous materials ${ }^{19}$ and zeolites ${ }^{20}$ have been used for the preparation of MMMs. Among them, zeolites with crystalline structures and well-defined pores in the range of nanometers due to their good adsorption properties as well as high mechanical and chemical stability have been widely employed for the preparation of pervaporation MMMs. Different zeolites such as NaA, ${ }^{21} \mathrm{NaY},{ }^{22} \mathrm{NaX},{ }^{23,24}$ ZIF-8 (ref. 25) 
and ZSM-5 (ref. 26-30) have been blended with polymers for the fabrication MMMs in the pervaporation process. Due to its high hydrophobicity, high surface area and uniform pore size distribution, ZSM-5 zeolite has been incorporated in the polymeric membranes to develop hydrophobic pervaporation MMMs toward the separation of organic compounds from aqueous solutions. For example, Zhang et al. $^{26}$ prepared the ZSM-5/hydroxyl terminated polybutadiene (HTPB)-based polyurethaneurea (PU) MMM for the pervaporation separation of isopropyl acetate from its aqueous solutions. Kittur et al. ${ }^{28}$ fabricated the ZSM-5/PDMS MMMs for the pervaporation separation of isopropanol from water. Vane et al. ${ }^{29}$ also incorporated the ZSM-5 zeolite into the PDMS membranes for the separation of ethanol from ethanol/water mixtures. Gu et al. ${ }^{30}$ fabricated the single layer ZSM-5/poly(ether-block-amide) (PEBA) membrane for the separation of ethyl acetate (EAc) from aqueous solutions.

Multi-layer mixed matrix membranes are another type of the membranes that have been used in the pervaporation process in recent years. The multi-layer mixed matrix membranes consist of a thin dense top layer containing inorganic fillers on porous sub-layers as a mechanical support. In previous studies, we reported the performance of nano zeolite NaX/polyvinyl alcohol (PVA)/polyethersulfone (PES) ${ }^{31}$ and carbon nanotubes/PVA/PES/ polyester ${ }^{32}$ multilayer mixed matrix membranes for dehydration of ethanol/water mixture via the pervaporation process. However, there are few studies about pervaporation separation of organic compounds from aqueous solutions using multilayer pervaporation MMMs.

Due to its low cost and low toxicity, EAc is widely used as a solvent in the chemical industry and as a raw material for the production of plasticizers, adhesive agents, drugs, perfumes, thinners, synthetic resins and varnishes. ${ }^{33,34}$ EAc is mainly synthesized via the esterification of acetic acid with ethanol. ${ }^{35}$ The product of the esterification process consists of water. Therefore, the EAc produced from the esterification process has a low concentration and needs to be concentrated and purified for use in various applications. In this area, the pervaporation, as an energy saving membrane process, has a high potential for the recovery of EAc from the aqueous solutions. ${ }^{36}$ In this work, the ZSM-5/PEBA/PES dual-layer MMMs were prepared by casting ZSM-5/PEBA/ $n$-butanol solution over the porous PES membrane as a support layer. The ZSM-5 zeolite nanoparticles were synthesized via the hydrothermal method and characterized using XRD, XRF and FESEM analysis. The ATR-FTIR, SEM, DSC and contact angle analysis were used to characterize the prepared membranes. The effect of ZSM-5 content on the performance of prepared MMMs toward the recovery of EAc from aqueous solutions was investigated. Also, the effect of feed concentration and operating temperature on the separation factor and permeation flux of the dual-layer MMMs in the laminar and turbulent flow regimes was studied. A full factorial design was used to develop the polynomial models for the separation factor and total flux as a function of EAc concentration and temperature. The main innovative aspect of this study is the use of nanofillers to prepare dual-layer mixed matrix membranes for the pervaporation separation of the EAc from the aqueous solutions. Another important contribution is the investigation of the effect of feed concentration, temperature and flow rate on the separation performance of the prepared mixed matrix membranes with the analysis of variance (ANOVA).

\section{Experimental}

\section{Materials}

The commercial Pebax® 2533 (80 wt\% poly(tetramethylene oxide) and $20 \mathrm{wt} \%$ polyamide) and PES (molecular weight of $58000 \mathrm{~g} \mathrm{~mol}^{-1}$, Ultrason E6020P) provided from Arkema Inc. (Paris, France) and BASF (Ludwigshafen, Germany) were used as the membrane materials, respectively. $N, N$-Dimethyl formamide (DMF) and $n$-butanol purchased from Merck Co. Ltd. (Darmstadt, Germany) were used as solvents for PES and PEBA, respectively. Tetrapropylammonium hydroxide (TPAOH), sodium hydroxide $(\mathrm{NAOH})$, aluminum isopropoxide supplied from Merck Co. Ltd. and tetraethyl orthosilicate (TEOS) supplied from Sigma Inc. (Sigma Aldrich, MO, USA) were used for synthesis of the ZSM-5 zeolite. Ethyl acetate was purchased from Merck Co. Ltd. and de-ionized water was mixed as the pervaporation feed.

\section{Synthesis of ZSM-5 zeolite}

ZSM-5 zeolite nanoparticles were synthesized from gel composition containing TPAOH, TEOS and water as solution A and aluminum isopropoxide, $\mathrm{NAOH}$, TPAOH and water as solution $\mathrm{B}$ by the following procedure. $4.22 \mathrm{~g}$ TPAOH and $8 \mathrm{~g}$ TEOS was initially dissolved in $20 \mathrm{~g}$ de-ionized water under stirring for $2 \mathrm{~h}$ (solution A). Solution B was prepared by dissolving $1.8 \mathrm{~g}$ $\mathrm{TPAOH}, 0.48 \mathrm{~g} \mathrm{NAOH}$ and 0.3 aluminum isopropoxide in $20 \mathrm{~g}$ de-ionized water. Solution A and solution B were then mixed together under stirring for a further $4 \mathrm{~h}$ to obtain a homogeneous gel. The prepared gel was then put to a Teflon lined steel autoclave at $200{ }^{\circ} \mathrm{C}$ for 2 days. Afterward, the synthesized zeolite was centrifuged and washed with deionized water three times. Then, the obtained solid product was dried at $110{ }^{\circ} \mathrm{C}$ for $12 \mathrm{~h}$. Finally, the synthesized zeolite was calcined at $550{ }^{\circ} \mathrm{C}$ for $5 \mathrm{~h}$.

\section{Fabrication of dual-layer mixed matrix membranes}

The phase inversion technique was used to fabricate the ZSM-5 filled PEBA/PES dual-layer MMMs. The porous PES ultrafiltration membrane was prepared as a support layer using the nonsolvent induced phase separation (NIPS) method as previously described. ${ }^{37-39}$ Briefly, the air bubble-free 16 wt $\%$ PES solution is prepared by dissolving the PES granules into the DMF under stirring for $24 \mathrm{~h}$ followed by de-aerating in a vacuum system for $1 \mathrm{~h}$. The PES membranes were prepared by casting the PES solution on a glass plate followed by immersing into the deionized water batch at room temperature, storing into another de-ionized water bath for $24 \mathrm{~h}$ and drying at room temperature for another $24 \mathrm{~h}$. The thickness of the prepared membranes was about $80 \pm 5 \mu \mathrm{m}$.

The neat PEBA and ZSM-5/PEBA membranes were prepared as a selective top layer on the surface of the PES sub-layer by the 
solvent evaporation induced phase separation method. ${ }^{\mathbf{4 0}}$ Briefly, the PEBA homogenous solution was achieved by dissolving PEBA granules in $n$-butanol under stirring for $5 \mathrm{~h}$ at $70{ }^{\circ} \mathrm{C}$. In addition, the suspensions of ZSM-5 zeolite were prepared by adding various amounts of ZSM- 5 nanoparticles to $n$-butanol under stirring for $1 \mathrm{~h}$ and sonication for $30 \mathrm{~min}$ in an ultrasonic (UP200S (200 W, $24 \mathrm{kHz}$ ), Hielscher Ultrasonics $\mathrm{GmbH}$, Germany). Then one sixth of the PEBA solution was added to the ZSM-5 suspension under stirring for $30 \mathrm{~min}$ followed by sonication in an ultrasonic for $15 \mathrm{~min}$. This procedure was continued until all of the polymer solution was added to the zeolite suspension. Afterwards, the prepared bubble-free dope solution containing ZSM-5 was casted over the porous PES support membrane. Finally, the prepared films were dried at room temperature for $24 \mathrm{~h}$, and then the residual solvent was evaporated by drying at $60{ }^{\circ} \mathrm{C}$ in an oven. The thickness of the top layer was about $20 \pm 2 \mu \mathrm{m}$.

Fig. 1 shows the schematic of the procedure used for the preparation dope solution containing ZSM-5 nanoparticles and fabrication of the PES membrane and dual-layer ZSM-5/PEBA/ PES membrane. The fabricated membranes were named as given in Table 1.
Table 1 The nomenclature of various prepared membranes

Membrane sample PEBA-2533 (wt\%) ZSM-5 (wt\%) n-Butanol (wt\%)

$\begin{array}{llll}\text { M0 } & 10 & 0.00 & 90.00 \\ \text { M05.0 } & 10 & 0.50 & 89.50 \\ \text { M07.5 } & 10 & 0.75 & 89.25 \\ \text { M10.0 } & 10 & 1.00 & 89.00 \\ \text { M12.5 } & 10 & 1.25 & 88.75 \\ \text { M17.5 } & 10 & 1.75 & 88.25\end{array}$

\section{Characterization tests}

XRD analysis. The powder's X-ray diffraction (XRD) instrument (Equinox 3000, Inel, France) at a temperature of $25^{\circ} \mathrm{C}$ and a scanning speed of $0.03^{\circ}(2 \theta) \mathrm{s}^{-1}$ was used to confirm the structure of the synthesized ZSM-5 zeolite.

XRF analysis. The elemental composition of the synthesized ZSM-5 zeolite was determined using X-ray fluorescence (XRF) analysis by a Philips spectrometer (PW 1404 spectrometer, Philips X'pert, Eindhoven, Netherlands).

ATR-FTIR analysis. The attenuated total reflection-Fourier transform infrared (ATR-FTIR) spectroscopy was used to characterize the functional groups of ZSM-5 particles, PEBA and
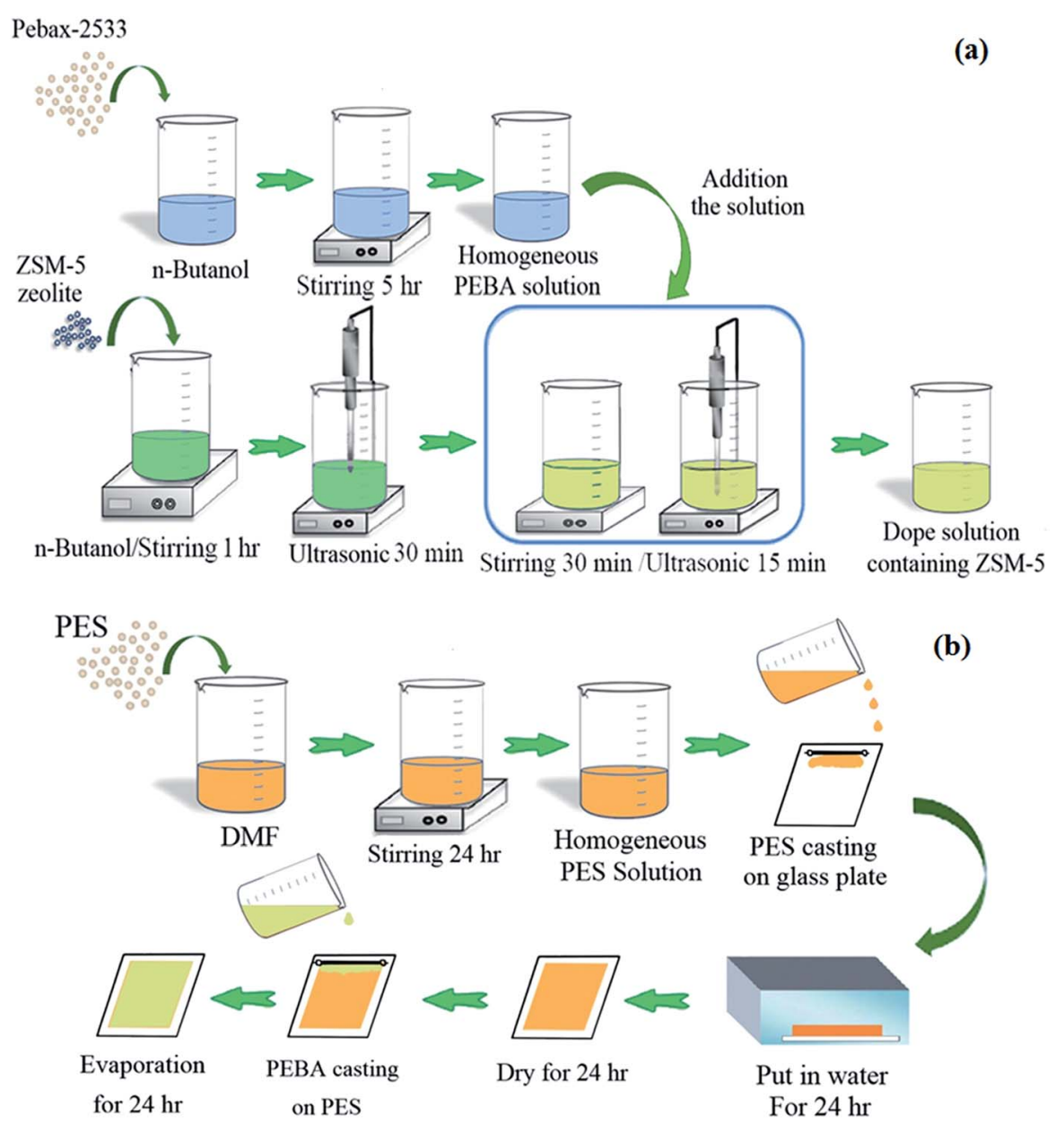

Fig. 1 The schematic of procedure used for the preparation dope solution containing ZSM-5 nanoparticles (a) and fabrication of dual layer ZSM5/PEBA/PES membrane (b). 
PEBA containing $10 \mathrm{wt} \%$ ZSM-5 membranes. The FTIR spectra were achieved by a Nicolet Nexus 670 spectrometer (Nicolet Instrument Co., Madison, WI, USA) over a wave number range of $3200-650 \mathrm{~cm}^{-1}$.

FESEM analysis. The morphological characteristics and particle size of the synthesized ZSM-5 zeolite were investigated using field emission scanning electron microscopy (FESEM) analysis by a TESCAN microscope (VEGA 3SB, TESCAN, Czech Republic).

SEM analysis. The SEM images were carried out using a scanning electron microscopy (SEM) device (model S-4160, Hitachi, NJ, USA) after gold coating to observe the surface and cross-section morphologies of the PEBA/PES and ZSM-5/PEBA/ PES membranes. For the cross-sectional SEM images, the samples were prepared by fracturing the water-wetted membrane in liquid nitrogen.

DSC analysis. The differential scanning calorimeter (DSC) analysis (Mettler-Toledo Inc., Switzerland) was carried out to determine the glass transient temperature $\left(T_{\mathrm{g}}\right)$ of the neat PEBA and ZSM-5/PEBA membranes. The samples were heated under pure argon atmosphere at a heating rate of $10{ }^{\circ} \mathrm{C} \mathrm{min}^{-1}$ from -100 to $220{ }^{\circ} \mathrm{C}$.

Contact angle. The optical contact angle device (OCA-20, Data physics GmbH, Filderstadt, Germany) was used to determine the water contact angle and hydrophobicity of the fabricated membranes. The water contact angle was measured at room temperature on the surface of each membrane in at least three different points and the mean values were reported.

\section{Pervaporation experiments}

To investigate the separation performance of the fabricated membrane, the pervaporation experiments were carried out using a cross flow flat plate and frame membrane module with an effective area of $35 \mathrm{~cm}^{2}$ for the separation of low concentrations of EAc from aqueous solutions. The membrane module had a feed channel with dimensions of $5 \mathrm{~cm}$ (width) $\times 7 \mathrm{~cm}$ (length) $\times 0.213 \mathrm{~cm}$ (height). The pervaporation apparatus was similar as described by Aroujalian and Raisi. ${ }^{\mathbf{4 1}}$ Each experiment was repeated three times and the average values were reported. The performance of the prepared MMMs with different ZSM-5 zeolite concentrations $(0,5,7.5,10,12.5$ and $17.5 \mathrm{wt} \%)$ was investigated in a laminar feed flow at a feed concentration of $5 \mathrm{wt} \%$ and a temperature of $40{ }^{\circ} \mathrm{C}$. Also, the effects of EAc concentration (1, 3 and $5 \mathrm{wt} \%)$ and operating temperature (30, 40 and $50{ }^{\circ} \mathrm{C}$ ) at laminar (feed flow rate of $4 \mathrm{~L} \mathrm{~min}^{-1}$ ) and turbulent flow regimes (feed flow rate of $13 \mathrm{~L} \mathrm{~min}^{-1}$ ) were evaluated on the separation of EAc/water mixtures using the M0 and M10.0 membranes. The EAc concentration in the permeate solutions was specified using a gas chromatography (Younglin 6000 M Series Gas Chromatography, Anyang, Korea) equipped with a flame ionization detector (FID) and a TRB-Wax capillary column (Teknokroma, Barcelona, Spain) $60 \mathrm{~m} \times 0.32 \mathrm{~mm}$ ID $\times$ $0.5 \mu \mathrm{m}$ film thickness. The carrier gas was helium with a column pressure of 10 psi. The temperature of the oven, injector and detector were 100,200 and $220{ }^{\circ} \mathrm{C}$, respectively.

The performances of the membranes for pervaporation separation of EAc/water mixture can be indicated in terms of total permeate flux $(J)$ and separation factor $(\alpha)$ as follows:

$$
\begin{aligned}
& J=\frac{W}{A \times t} \\
& \alpha=\frac{\frac{Y_{\mathrm{EAc}}}{Y_{\text {water }}}}{\frac{X_{\mathrm{EAc}}}{X_{\text {water }}}}
\end{aligned}
$$

where $W, A, t, Y$ and $X$ are the mass of the collected permeate sample, the effective area of the membrane, process time and mass fractions of components in the permeate and feed solutions, respectively.

\section{Results and discussion}

\section{ZSM-5 zeolite characterization}

Fig. 2a shows the XRD pattern of the synthesized ZSM-5 zeolite. There are four sharp diffraction peaks at $2 \theta=7.9,8.8,23.9$ and
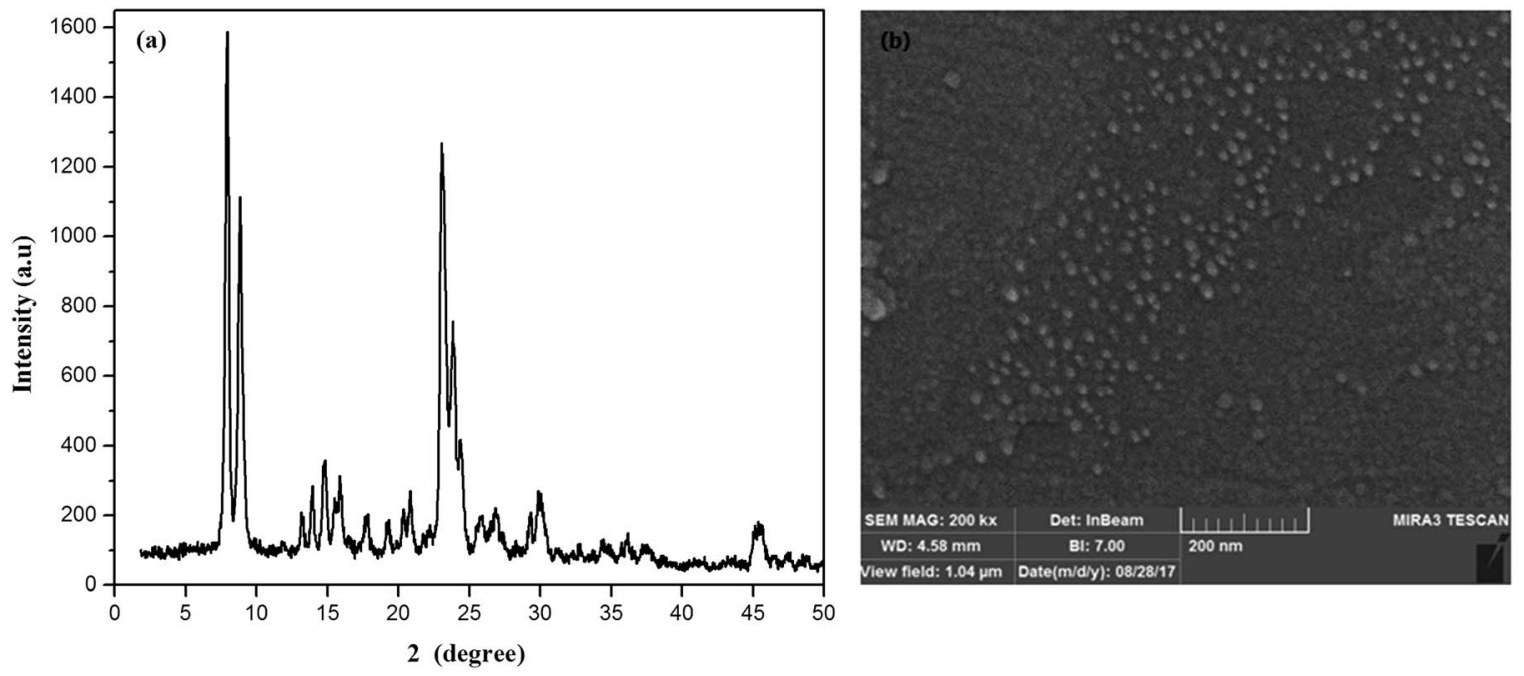

Fig. 2 The XRD pattern (a) and FESEM image (b) of the synthesized ZSM-5 zeolite nanoparticles. 
$24.4^{\circ}$ which are attributed to the ZSM-5 zeolite. ${ }^{42}$ The sharp peaks in the XRD pattern of zeolite indicated the pure crystalline structure of synthesized zeolites. The crystal size of zeolite particles obtained from the well-known Scherrer's equation was found to be $32.3 \mathrm{~nm}$.

The FESEM image of ZSM-5 zeolite (Fig. 2b) showed that the almost spherical-like ZSM-5 particles with a uniform size distribution in the range of $20-50 \mathrm{~nm}$ were synthesized. The average particle size of ZSM-5 zeolite particles was $35 \mathrm{~nm}$. The $\mathrm{XRF}$ result on the synthesized ZSM-5 zeolite indicated that the $\mathrm{SiO}_{2} / \mathrm{Al}_{2} \mathrm{O}_{3}$ ratio was found to be 52 .

\section{Mixed matrix membranes characterization}

Surface chemistry of membranes. The surface chemistry of the prepared membranes was characterized by the ATR-FTIR and water contact tests. The ATR-FTIR analysis was applied to detect the changes in the surface functional groups of the membrane in the presence of ZSM-5 particles. The ATR-FTIR spectra of the synthesized ZSM-5 zeolite, neat PEBA membrane and the PEBA membrane containing $10 \mathrm{wt} \% \mathrm{ZSM}-5$ are illustrated in Fig. 3. In ATR-FTIR spectrum of the ZSM-5 zeolite, the absorption bands at a wave number of $800 \mathrm{~cm}^{-1}$ is assigned to the $\mathrm{SiO}_{4}$ tetrahedron units and the strong absorption band in the range of $1000-1200 \mathrm{~cm}^{-1}$ is attributed to the vibration of $\mathrm{SiO}_{4}$ and $\mathrm{AlO}_{4}$ tetrahedra for the $\mathrm{ZSM}-5$ zeolite. ${ }^{43}$ For both neat and mixed matrix membranes, the asymmetric $\mathrm{CH}_{2}$ bands are observed in the range of $2800-2900 \mathrm{~cm}^{-1}$. The stretching $\mathrm{C}=\mathrm{O}$ at $1730 \mathrm{~cm}^{-1}$ and amide $\mathrm{I}$ adsorption band at $1640 \mathrm{~cm}^{-1}$ are assigned to urethane groups of PEBA. The peaks at wave numbers of 1350-1400, 1150-1240 and $720 \mathrm{~cm}^{-1}$ are related to $\mathrm{CCH}$ bending, amide III stretching group and stretching $\mathrm{C}-\mathrm{C}$ group, respectively. The adsorption bands at a wave number of about 1100 and $800 \mathrm{~cm}^{-1}$ confirmed the ether function group in the PEO block of PEBA. The observed new bands at a wave number of 1100 and $800 \mathrm{~cm}^{-1}$ in the FTIR spectrum of MMM show the presence of ZSM-5 zeolite in the PEBA matrix. ${ }^{40}$

Contact angle. To investigate the hydrophobicity of the prepared pure PEBA and zeolite filled PEBA/PES membranes,

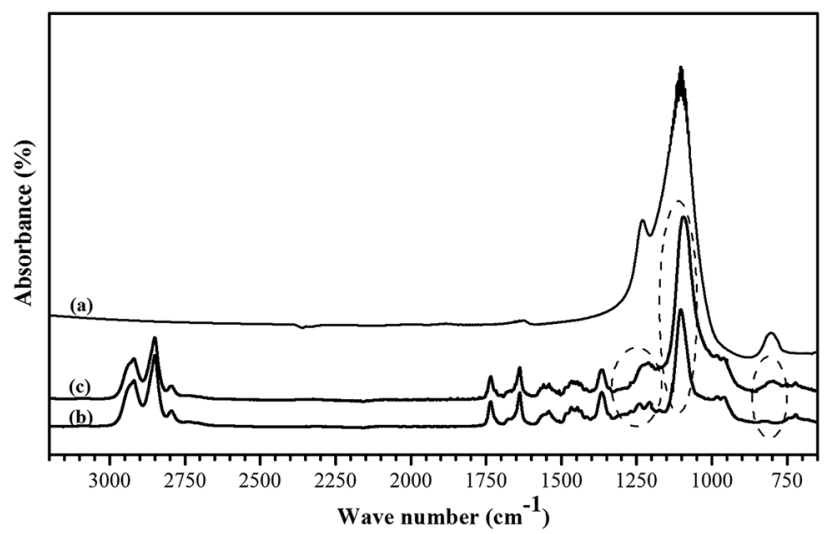

Fig. 3 The ATR-FTIR spectra of the ZSM-5 zeolite (a), neat PEBA membrane (b) and PEBA membrane containing 10 wt\% ZSM-5 (c).
Table 2 The water contact angle of various membranes

\begin{tabular}{ll}
\hline Membrane & Contact angle $\left(^{\circ}\right)$ \\
\hline M0 & $81 \pm 2.1$ \\
M05.0 & $86 \pm 1.9$ \\
M07.5 & $90 \pm 2.9$ \\
M10.0 & $92 \pm 1.7$ \\
M12.5 & $94 \pm 2.5$ \\
& $96 \pm 1.6$
\end{tabular}

the water contact angle measurements on the membranes were carried out. The results of contact angle on the neat PEBA/PES membrane and MMMs containing 5, 7.5, 10, 12.5 and 17.5 wt\% ZSM-5 zeolite are given in Table 2. As shown, the contact angle of the prepared membranes was increased from 81 to $96^{\circ}$ by increasing zeolite content in the PEBA/PES membranes from 0 to $17.5 \mathrm{wt} \%$ zeolite. These results proved enhancement in the hydrophobicity of MMMs by increasing the loading of the ZSM-5 zeolite nanoparticles content into the PEBA membrane. Similar observations were reported in previous studies. For example, Zhang et al. ${ }^{26}$ showed that the hydrophobicity of HTPB-PU/ZSM-5 membranes was enhanced from 88.5 to $93^{\circ}$ with increasing ZSM-5 loading content from 0 to $20 \mathrm{wt} \%$. Also, Gu et al. ${ }^{30}$ observed the enhancement in contact angle of zeolite filled PEBA membranes from 82 to $97^{\circ}$ by increasing the zeolite concentration up to $40 \mathrm{wt} \%$.

Morphology of membranes. The SEM images of the top surface and cross-section of the PEBA/PES membrane and MMMs containing 5, 10, 12.5 and $17.5 \mathrm{wt} \%$ zeolite are illustrated in Fig. 4. As shown in Fig. 4a, the surface of the M0 membrane was smooth without any pores. The surface images of MMMs indicated that the bright spots on the membrane surface were increased by increasing zeolite concentration which represents the zeolite particles on the top surface of the MMMs. Obviously, the zeolite content on the membrane surface increased by enhancement of incorporated zeolites into the membranes. The ZSM-5 particles were well dispersed in the MMMs containing 5 and $10 \mathrm{wt} \%$ zeolite. The lower zeolite loading in MMMs resulted in good distribution of zeolite particles on the membrane surface. This is while, the zeolite particles were aggregated in ZSM-5/PEBA/PES MMMs containing 12.5 and $17.5 \mathrm{wt} \%$ zeolite. The agglomeration of zeolite particles on the membrane surface containing $17.5 \mathrm{wt} \%$ zeolite was higher than that of the MMMs surface containing $12.5 \mathrm{wt} \%$ zeolite. The cross-sectional SEM image of the neat PEBA/PES membrane indicated that the prepared PEBA/PES defect-free has a dense top PEBA layer with a thickness of about $20 \pm 2$ $\mu \mathrm{m}$ on a porous PES support with a finger like structure and thickness of about $80 \pm 5 \mu \mathrm{m}$. The cross-section SEM images of the zeolite filled PEBA/PES membranes showed that the ZSM-5 zeolite particles were distributed on the top layer of MMMs. As shown in Fig. 4b and c, the zeolite particles were uniformly dispersed in the PEBA network without any agglomeration and void in the zeolite/polymer interface of MMMs containing 5 and $10 \mathrm{wt} \%$ zeolite. This is while, the agglomeration of the zeolite 

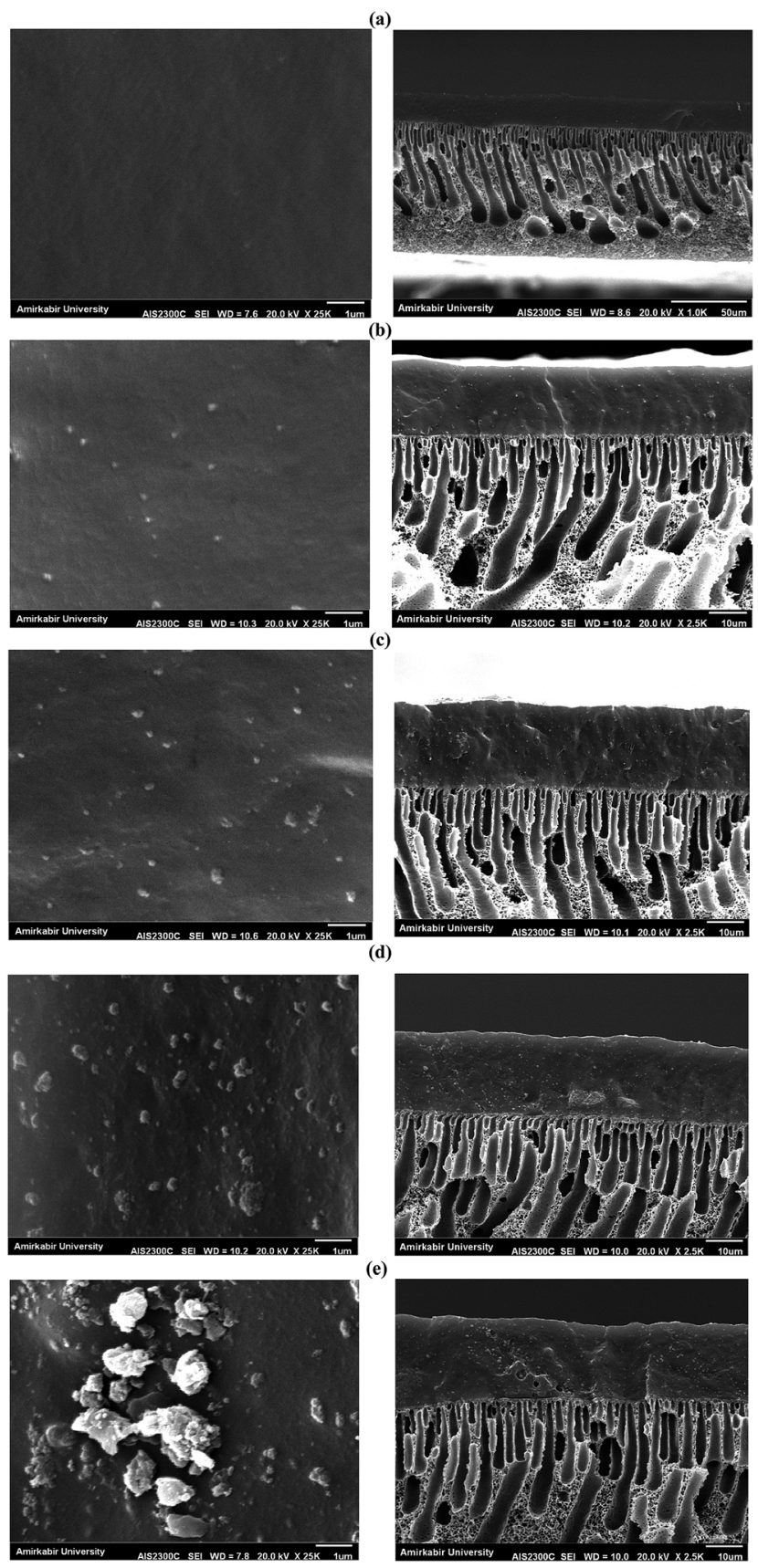

Fig. 4 The SEM images of top surface (left) and cross section (right) of the prepared membranes: M0 (a), M05.0 (b), M10.0 (c), M12.5 (d) and M17.5 (e).

particles is observed in the cross-sectional SEM images of ZSM5/PEBA/PES MMM containing 12.5 and $17.5 \mathrm{wt} \%$ zeolite.

Thermal behavior of membranes. The DSC analysis was used to determine the thermal decomposition behavior of the prepared membranes and the interaction between the PEBA and ZSM-5 zeolite. Typically, the DSC plots of the neat PEBA and PEBA containing $10 \mathrm{wt} \%$ ZSM-5 membranes are illustrated in Fig. 5. As shown, by adding ZSM-5 zeolite into the polymer matrix, the glass transient temperature $\left(T_{\mathrm{g}}\right)$ was increased from $-77.5^{\circ} \mathrm{C}$ for the neat PEBA membrane to $-72.5^{\circ} \mathrm{C}$ for the ZSM-

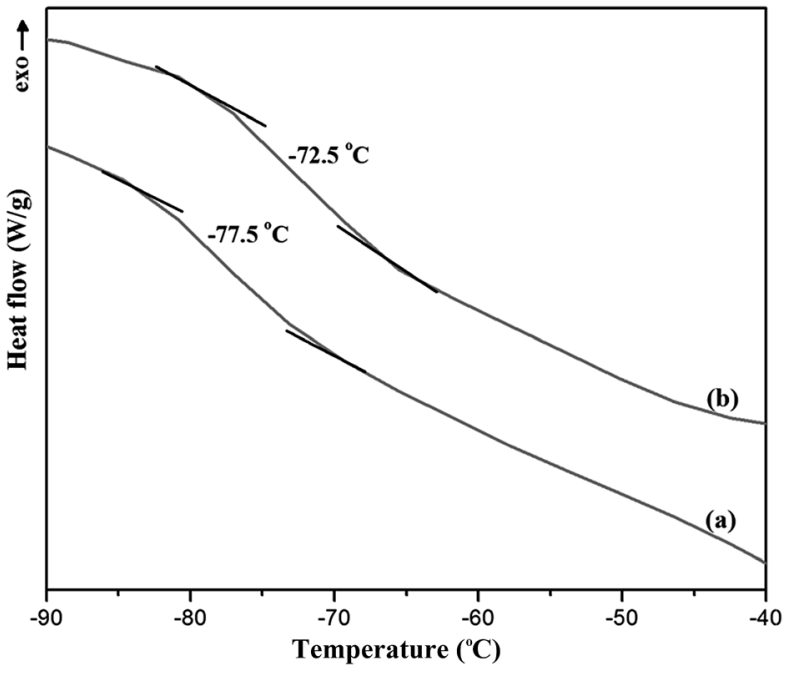

Fig. 5 The DSC curves of the neat PEBA membrane (a) and PEBA membrane containing 10 wt\% ZSM-5 (b).

5 filled PEBA membrane containing $10 \mathrm{wt} \%$ zeolite. The increasing $T_{\mathrm{g}}$ could be attributed to rigidifying of the polymer chains around the zeolite particles and increasing interfacial interaction. Zarshenas et $a l .^{40}$ indicated that the $T_{\mathrm{g}}$ of the pure Pebax- 1657 membrane increased from $-57.83{ }^{\circ} \mathrm{C}$ to $-50.42{ }^{\circ} \mathrm{C}$ by loading $4 \mathrm{wt} \% \mathrm{NaX}$ nanozeolite into the PEBA membrane. Yu et al. ${ }^{44}$ also observed the enhancement in $T_{\mathrm{g}}$ of the Pebax-1657 membrane by loading different fillers including silica nanoparticles, polystyrene (PS) colloids and carbon nanotubes (CNTs) into the PEBA membrane. The $T_{\mathrm{g}}$ of -77.1 for pure PEBA-2533 was reported by Rahman et al. ${ }^{45}$

\section{Mixed matrix membranes pervaporation performance}

Effect of zeolite loading concentration. The effect of zeolite loading content in the ZSM-5 filled PEBA/PES dual-layer membranes on the pervaporation performance for a feed

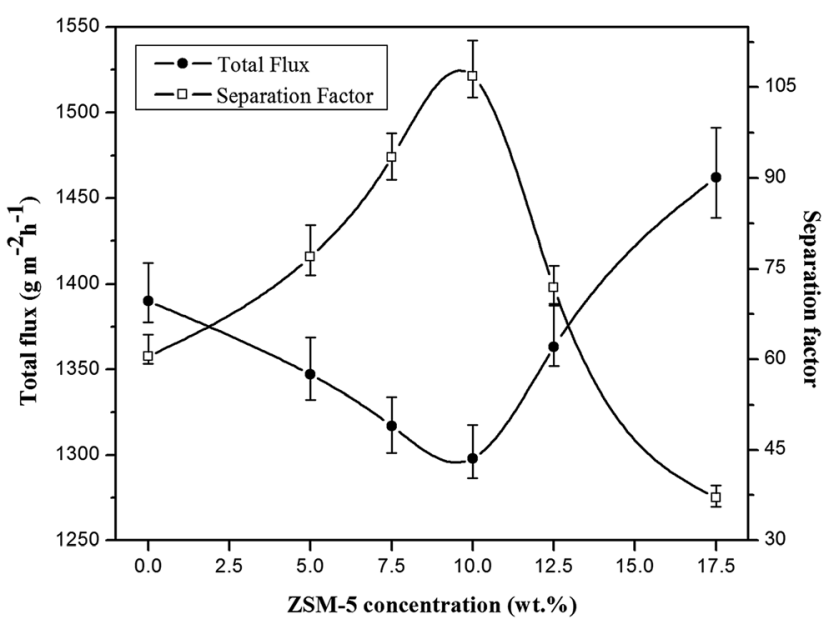

Fig. 6 The effect of ZSM-5 concentration on the total flux and separation factor of various prepared membranes (EAc concentration $=5 \mathrm{wt} \%$ and $T=40^{\circ} \mathrm{C}$ ). 
concentration of $5 \mathrm{wt} \%$ EAc at operating temperature of $40{ }^{\circ} \mathrm{C}$ in the laminar flow regime is illustrated in Fig. 6. As indicated in this figure, the separation factor was significantly increased by an enhancement in the zeolite content in membranes up to $10 \mathrm{wt} \%$ and a further increase in the zeolite concentration resulted in a decrease in the separation factor. The gradual decrease in the total permeate flux was obtained by increasing ZSM-5 loading up to $10 \mathrm{wt} \%$ zeolite. By loading zeolite into the PEBA/PES membranes, the EAc and water molecular movement were decreased in the membrane matrix and consequently, the decrease in total permeation flux of the zeolite filled PEBA/PES membranes was observed compared with the neat PEBA/PES dual-layer membrane. The decrease in the EAc and water movement in the membrane matrix after loading ZSM- 5 can be attributed to the polymer chain rigidification after incorporation of ZSM-5 nanoparticles into the polymer matrix. In the mixed matrix membranes, the mobility of the polymer chains in the region directly contacting the inorganic particles can be inhibited relative to that for the bulk polymer, this phenomenon is called polymer chain rigidification. The polymer chain rigidification can be easily detected by increasing $T_{\mathrm{g}}$ with the addition of zeolite nanoparticles. ${ }^{46}$ The inhibited movement of the polymer chains near the zeolite particle is the major cause of $T_{\mathrm{g}}$ shift. ${ }^{47}$ As confirmed by the DSC analysis, the rigidification of polymer chains was observed through the increasing of $T_{\mathrm{g}}$ by loading the zeolite into the PEBA/PES membrane.

The permeation flux was increased at zeolite concentrations higher than $10 \mathrm{wt} \%$. Defects in the top layer of the MMMs could be responsible for increasing the permeation flux of the duallayer membrane containing 12.5 and $17.5 \mathrm{wt} \% \mathrm{ZSM}-5$. These defects were created in the membrane top layer due to agglomeration of ZSM-5 nanoparticles at high zeolite
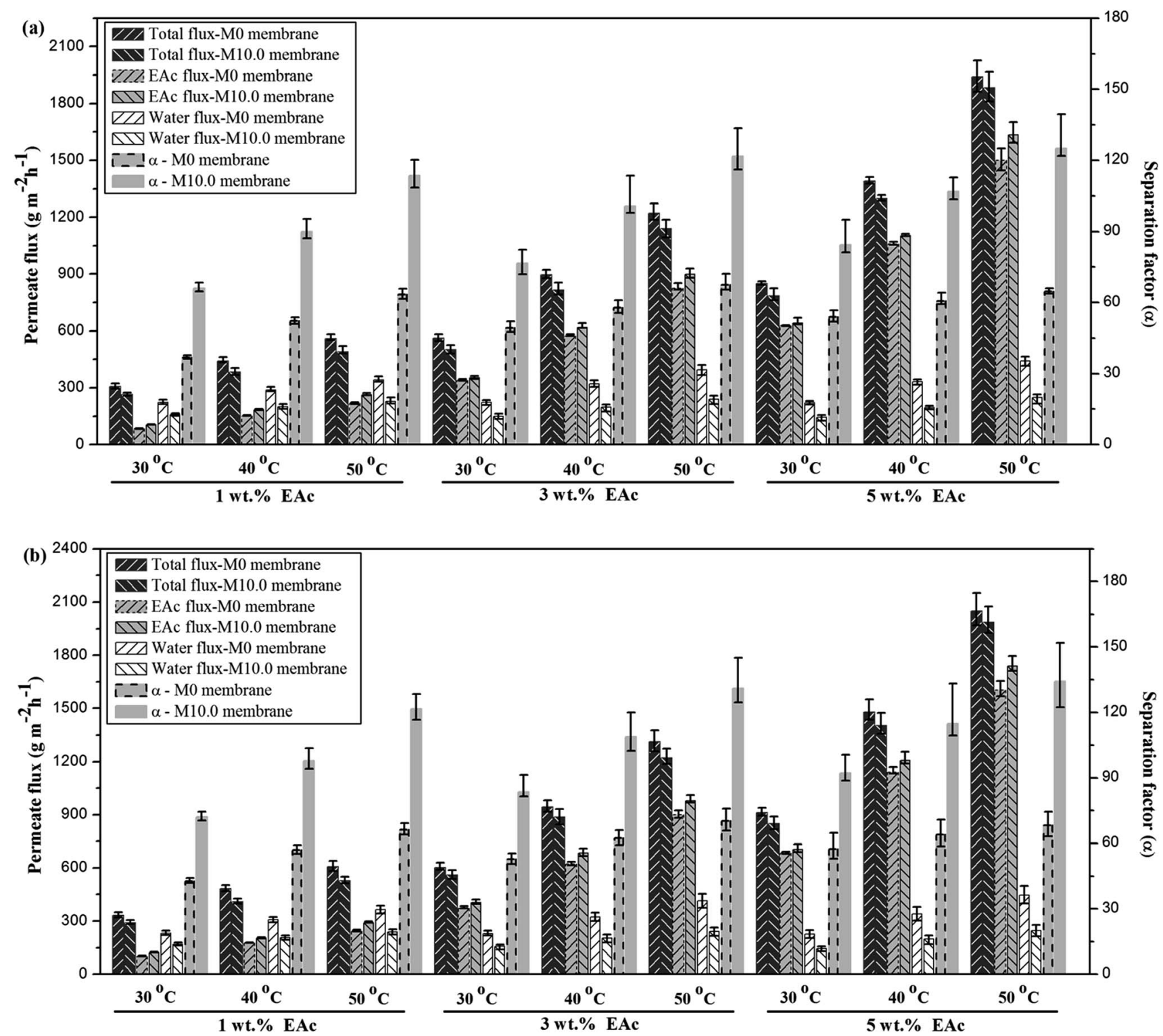

Fig. 7 The effect of feed concentration and temperature on the total, EAc and water fluxes and also separation factor for the M0 and M10.0 membranes at laminar (a) and turbulent (b) feed flow regimes. 
concentrations, as detected by the SEM analysis (Fig. 4d and e). The increase in separation factor by increasing zeolite loading content up to $10 \mathrm{wt} \%$ could be attributed to the enhancement in hydrophobicity of the membrane and increasing the sorption of EAc molecules by adding ZSM-5 zeolite into the PEBA/PES membranes as confirmed by contact angle tests. Based on the results of the contact angle test, by loading ZSM-5 zeolite into the PEBA matrix, the contact angle of the prepared membranes was increased which resulted in more selective sorption of the EAc molecules using the MMMs. The aggregation of ZSM-5 nanoparticles in MMMs at concentrations higher than $10 \mathrm{wt} \%$ zeolite resulted in defects between the polymer chains, which allowed the simultaneous permeation of EAc and water and led to a decrease in the separation factor. Therefore, the best separation performance was observed for the dual-layer ZSM-5/ PEBA/PES membrane containing $10 \mathrm{wt} \%$ zeolite. Zhang et al. ${ }^{26}$ indicated that the optimum performance of the HTPB-PU/ZSM5 membrane was obtained by loading $20 \mathrm{wt} \%$ ZSM-5 into the membranes for pervaporation separation of isopropyl acetate from aqueous solution. Gu et al. ${ }^{30}$ observed the enhancement in EAc/water separation factor by enhancement of the ZSM-5 loading from 0 to $10 \mathrm{wt} \%$ into the single layer PEBA membrane.

Effect of pervaporation operating parameters. The simultaneous effects of feed concentration, temperature and feed flow regime on the separation factor, water and EAc partial fluxes and total flux of the M0 and M10.0 membranes are illustrated in Fig. 7. In the following, a parametric study was done to investigate the influence of pervaporation operating parameters on the separation performance of the prepared membranes.

The comparison of the separation factor of both M0 and M10.0 membranes at the turbulent flow regime showed that the separation factor of both membranes in the turbulent flow regime was higher than the separation factor at laminar flow regime in different feed concentrations and operating temperatures as indicated in Fig. 7. The EAc permeation flux and total flux for both M0 and M10.0 membranes at the turbulent flow regime were higher than the laminar flow regime. By increasing the feed flow rate, the mass transfer rate of EAc from the bulk solution to the membrane surface was increased and subsequently the EAc partial flux and total flux were enhanced. This trend can be explained based on the resistance-in-series model in which the total mass transport resistance through a duallayer membrane is the sum of the liquid boundary-layer resistance, intrinsic membrane active layer resistance and support layer resistance. ${ }^{48}$ When the liquid boundary-layer resistance is much larger than the intrinsic membrane resistance, the mass transfer in the boundary-layer becomes rate-limiting. ${ }^{49}$ Therefore, a change in the feed flow regime from laminar to turbulent leads to a decrease in the concentration polarization near the membrane surface and a reduction in the boundary-layer thickness, and consequently the permeation rate across the membrane enhances. These observations are consistent with the results in the literature. For instance, Dutta and Sikdar ${ }^{50}$ reported enhancement in the separation factor of trichloroethane with increasing feed flow rate. Psaume et al. ${ }^{51}$ indicated that the permeation flux was increased by increasing the Reynolds number. Li et al. ${ }^{52}$ observed an enhancement in both total flux and separation factor of the cellulose acetate/ polydimethylsiloxane membrane for the pervaporation separation of acetone from aqueous solution by increasing flow rate. The permeation fluxes and separation factor as a function of feed concentration for the M0 and M10.0 membranes at a temperature of $40{ }^{\circ} \mathrm{C}$ and turbulent feed flow is indicated in Fig. 8. As shown, the separation factor, total flux and EAc partial flux of both membranes increased by variation in feed concentration from 1 to $5 \mathrm{wt} \%$. The composition of feed solution has a remarkable influence on the component sorption into the membrane and on the component diffusion through the membrane, because the kinetic and thermodynamic properties of the permeating species and membrane are significantly affected by the component concentration in the feed solution. The enhancement in EAc permeation flux by increasing feed concentration could be attributed to increasing the driving force and acceleration of the diffusion rate of EAc molecular during the pervaporation process. Increasing EAc feed concentration will enhance the concentration gradient across the
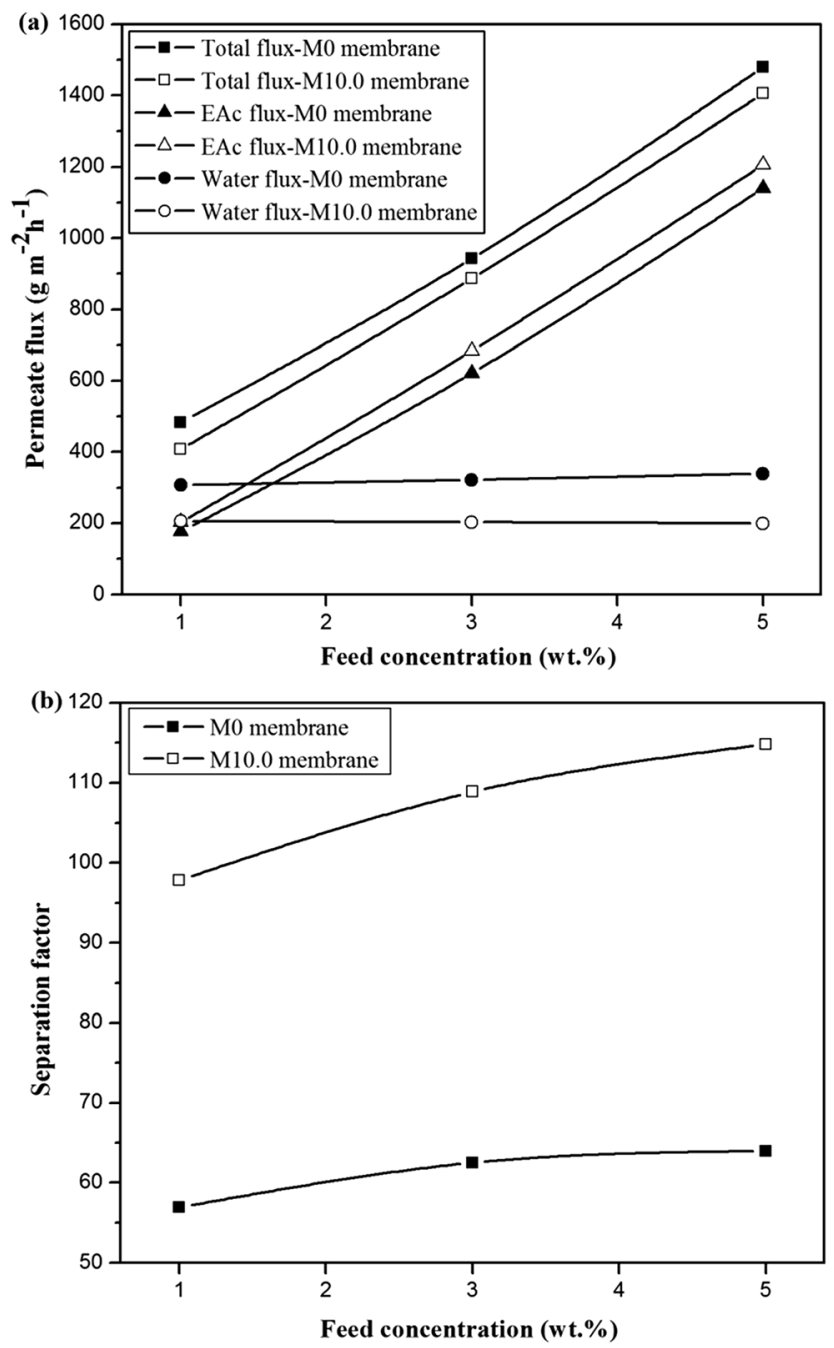

Fig. 8 The effect of feed concentration on the permeate fluxes (a) and separation factor (b) for the $\mathrm{M0}$ and $\mathrm{M} 10.0$ membranes at temperature of $40{ }^{\circ} \mathrm{C}$ and turbulent flow. 
membrane; thereby the EAc permeation rate through the membrane increases. Also, the high sorption of EAc relative to water into the membranes due to the hydrophobic nature of the membrane is responsible for increasing the separation factor by increasing the EAc concentration in the feed solution. As confirmed by contact angle and FTIR tests, the hydrophobic structure of the PEBA/PES and ZSM-5/PEBA/PES membranes resulted in the faster sorption rate of EAc compared with the sorption rate of water and an enhancement in interaction between the EAc and membrane resulted in an increase in the separation factor by an enhancement in EAc concentration. The gradual increase in the water partial flux was observed by increasing EAc feed concentration for the M0 membrane, whereas the insignificant change in water flux was achieved by increasing feed concentration for the M10.0 membrane, as indicated in Fig. 8a. This behavior can be ascribed to the membrane swelling phenomenon. The membrane swelling due to an increase in the feed concentration affects the separation performance of the membrane. The swelling of the membrane leads to a membrane with higher free volume and unrestricted transfer of the permeating components through the membrane. When a higher EAc concentration feed solution was in contact with the neat PEBA/PES membrane, the membrane swelling occurred. This resulted in easier transport of water molecules through the swollen membrane, and consequently the water partial flux enhanced with the EAc feed concentration. The constant water permeation flux with an enhancement in the feed concentration for the M10.0 membranes indicated that the incorporation of ZSM-5 nanoparticles into the PEBA matrix prevents the membrane swelling.

The permeation fluxes and separation factor as a function of feed temperature for the M0 and M10.0 membranes for the EAc feed concentration of $1 \mathrm{wt} \%$ and turbulent feed flow is shown in Fig. 9. It can be seen that all permeation fluxes and EAc separation factor increased by enhancing the feed temperature. Since the viscosity and diffusivity of components in the feed solution as well as the solubility and diffusivity of permeating components in the membrane are temperature dependent, a change in the operating temperature has a significant influence on the separation properties of the membrane. Moreover, in the dense polymeric membranes, the permeating components diffuse in the membrane via the free volumes, which are produced by jumping of the polymer chains. The frequency of polymer chain motions enhances by increasing temperature. Consequently the free volume in the polymer matrix increases and leads to higher permeation rate through the membrane. Therefore, both EAc and water partial fluxes and total flux enhance as the operating temperature goes to higher levels. Furthermore, Fig. 9b indicates that the separation factor enhanced by increasing the operating temperature. The EAc and water partial fluxes enhance with temperature, but the EAc flux is more sensitive to variation in the feed temperature because of its higher activation energy for the permeation. Thus, the separation factor that is proportional to the ratio of the EAc flux to water flux increases by enhancing the operating temperature. Similar reports are presented in the literature for the effect of feed concentration and temperature on the permeation flux and separation factor. For example, Zhang et al. ${ }^{26}$ observed an enhancement in the isopropyl acetate and water partial flux, total flux and separation factor using the HTPB-PU/ZSM-5 membrane by increasing feed concentration from 0.2 to $1 \mathrm{wt} \%$ and operating temperature from 30 to $60{ }^{\circ} \mathrm{C}$. Gu et al. ${ }^{30}$ investigated the effect of feed concentration and temperature on the pervaporation performance of the ZSM-5/ PEBA membrane toward low concentrations of EAc from aqueous solution. They found the significant enhancement in the EAc partial flux, total flux and separation factor as well as gradual reduction in the water partial flux by increasing feed concentration. Both separation factor and total flux were also enhanced by increasing the feed temperature up to $50{ }^{\circ} \mathrm{C}$. Tan et $a l^{53}$ also observed that both separation factor and total permeation flux for separation of $n$-butanol/water mixtures using the ZSM-5/PEBA membrane were increased by enhancing temperature and feed concentration.

Statistical analysis. Analysis of variance (ANOVA) was used to investigate the interaction effect of feed concentration and
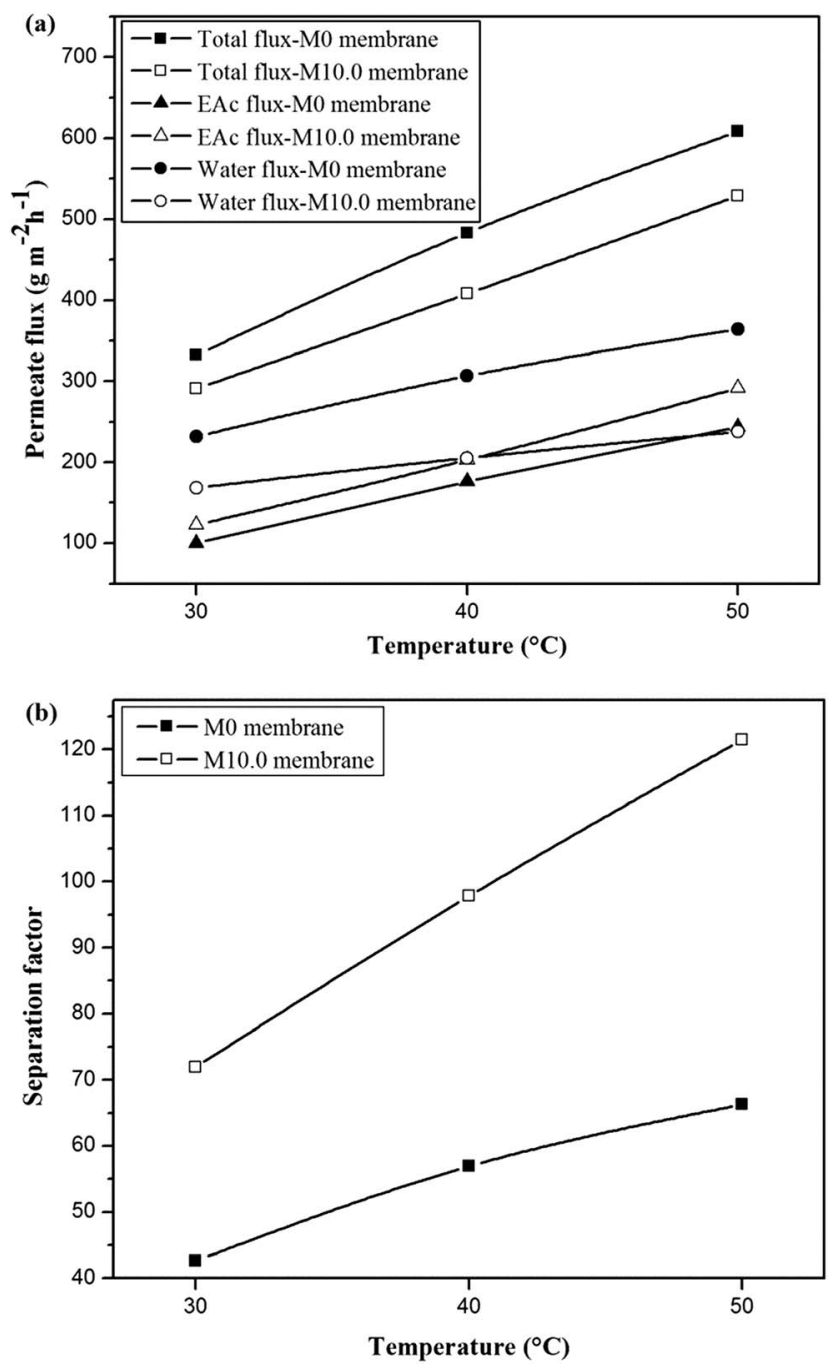

Fig. 9 The effect of feed temperature on the permeation fluxes (a) and separation factor (b) for the M0 and M10.0 membranes for EAc feed concentration of $1 \mathrm{wt} \%$ at turbulent flow. 
Table 3 The ANOVA results for the MO membranes

\begin{tabular}{|c|c|c|c|c|c|c|c|c|c|c|c|c|c|}
\hline \multirow[b]{3}{*}{ Source } & \multirow[b]{3}{*}{ DF } & \multicolumn{6}{|c|}{ Laminar flow regime } & \multicolumn{6}{|c|}{ Turbulent flow regime } \\
\hline & & \multicolumn{3}{|c|}{ Separation factor } & \multicolumn{3}{|l|}{ Total flux } & \multicolumn{3}{|c|}{ Separation factor } & \multicolumn{3}{|l|}{ Total flux } \\
\hline & & $\begin{array}{l}\text { Sum } \\
\text { of squares }\end{array}$ & $\begin{array}{l}F \\
\text { factor }\end{array}$ & $P$ factor & $\begin{array}{l}\text { Sum of } \\
\text { squares }\end{array}$ & $F$ factor & $P$ factor & $\begin{array}{l}\text { Sum of } \\
\text { squares }\end{array}$ & $F$ factor & $P$ factor & $\begin{array}{l}\text { Sum of } \\
\text { squares }\end{array}$ & $F$ factor & $P$ factor \\
\hline Regression & 5 & 713.367 & 154.60 & 0.001 & 2217883 & 10779.99 & 0.000 & 604.314 & 417.71 & 0.000 & 2458380 & 5845.55 & 0.000 \\
\hline Linear & 2 & 633.376 & 343.16 & 0.000 & 2041397 & 24805.46 & 0.000 & 544.613 & 941.10 & 0.000 & 2271367 & 13502.18 & 0.000 \\
\hline$X_{1}$ & 1 & 119.260 & 129.23 & 0.001 & 1374731 & 33409.30 & 0.000 & 92.905 & 321.08 & 0.000 & 1518054 & 18048.2 & 0.000 \\
\hline$X_{2}$ & 1 & 514.115 & 557.09 & 0.000 & 666667 & 16201.62 & 0.000 & 451.707 & 1561.12 & 0.000 & 753313 & 8956.16 & 0.000 \\
\hline Square & 2 & 19.151 & 10.38 & 0.045 & 924 & 11.23 & 0.040 & 18.741 & 32.39 & 0.009 & 1252 & 7.44 & 0.069 \\
\hline$X_{1} \times X_{1}$ & 1 & 17.543 & 19.01 & 0.022 & 910 & 22.12 & 0.018 & 13.957 & 48.24 & 0.006 & 1250 & 14.86 & 0.031 \\
\hline$X_{2} \times X_{2}$ & 1 & 1.608 & 1.74 & 0.279 & 14 & 0.35 & 0.598 & 4.784 & 16.53 & 0.027 & 2 & 0.02 & 0.887 \\
\hline Interaction & 1 & 60.840 & 65.93 & 0.004 & 175561 & 4266.56 & 0.000 & 40.960 & 141.56 & 0.001 & 185761 & 2208.52 & 0.000 \\
\hline$X_{1} \times X_{2}$ & 1 & 60.840 & 65.93 & 0.004 & 175561 & 4266.56 & 0.000 & 40.960 & 141.56 & 0.001 & 185761 & 2208.52 & 0.000 \\
\hline Residual error & 3 & 2.769 & & & 123 & & & 0.868 & & & 252 & & \\
\hline Total & 8 & 716.135 & & & 2218006 & & & 605.182 & & & 2458632 & & \\
\hline
\end{tabular}

operating temperature on the separation factor and total permeation flux of the M0 and M10.0 membranes as well as the simultaneous optimization of parameters for the optimum performance of the membranes at laminar and turbulent flow regimes. The ANOVA results for the separation factor and total permeation flux of the M0 and M10.0 membranes as a function of feed concentration and operating temperature are listed in Tables 3 and 4, respectively. The large value of $F$ indicates that most of the variations in the response could be explained by the regression equation. The $P$-value lower than 0.05 , indicates the

Table 4 The ANOVA results for the M10.0 membranes

\begin{tabular}{|c|c|c|c|c|c|c|c|c|c|c|c|c|c|}
\hline & & \multicolumn{3}{|c|}{ Separation factor } & \multicolumn{3}{|l|}{ Total flux } & \multicolumn{3}{|c|}{ Separation factor } & \multicolumn{3}{|l|}{ Total flux } \\
\hline Regression & 5 & 3344.74 & 1110.54 & 0.000 & 2163062 & 1621.45 & 0.000 & 3664.84 & 2246.74 & 0.000 & 2403742 & 5552.44 & 0.000 \\
\hline$X_{2}$ & 1 & 2958.37 & 4911.29 & 0.000 & 640920 & 2402.20 & 0.000 & 3221.56 & 9874.90 & 0.000 & 689526 & 7963.73 & 0.000 \\
\hline Square & 2 & 12.21 & 10.13 & 0.046 & 2377 & 4.45 & 0.126 & 15.59 & 23.90 & 0.014 & 1040 & 6.01 & 0.089 \\
\hline$X_{1} \times X_{1}$ & 1 & 8.50 & 14.11 & 0.033 & 2112 & 7.92 & 0.067 & 11.46 & 35.12 & 0.010 & 968 & 11.18 & 0.044 \\
\hline$X_{2} \times X_{2}$ & 1 & 3.71 & 16.16 & 0.049 & 264 & 0.99 & 0.393 & 4.14 & 12.68 & 0.038 & 72 & 0.83 & 0.429 \\
\hline Interaction & 1 & 11.46 & 19.02 & 0.022 & 189660 & 710.86 & 0.000 & 13.69 & 41.96 & 0.007 & 201152 & 2323.22 & 0.000 \\
\hline$X_{1} \times X_{2}$ & 1 & 11.46 & 19.02 & 0.022 & 189660 & 710.86 & 0.000 & 13.69 & 41.96 & 0.007 & 201152 & 2323.22 & 0.000 \\
\hline
\end{tabular}

Table 5 The predicted response and constant parameters of eqn (3)

\begin{tabular}{|c|c|c|c|c|c|c|}
\hline Separation factor of the M0 membrane at laminar flow & -15.61 & 14.47 & 1.51 & -0.74 & 0.000 & -0.195 \\
\hline Total flux of the M0 membrane at laminar flow & 147.00 & -211.00 & 1.91 & 5.33 & 0.000 & 10.47 \\
\hline Total flux of the M0 membrane at turbulent flow & 129.75 & -217.00 & 3.11 & 6.25 & 0.000 & 10.78 \\
\hline Separation factor of the M10.0 membrane at laminar flow & -36.52 & 10.36 & 3.56 & -0.51 & -0.013 & -0.085 \\
\hline Total flux of the M10.0 membrane at laminar flow & 184.38 & -248.83 & 0.02 & 8.13 & 0.000 & 10.89 \\
\hline
\end{tabular}


significant term in surface response analysis. By elimination of insignificant terms $(p>0.05)$ from the full quadratic model, the polynomial equations for the separation factor and total permeation flux of the membranes can be expressed as follows:

$$
Y=\beta_{0}+\beta_{1} X_{1}+\beta_{2} X_{2}+\beta_{3} X_{1}^{2}+\beta_{4} X_{2}^{2}+\beta_{5} X_{1} X_{2}
$$

where $Y$ is the predicted response by the model, $X_{1}$ and $X_{2}$ are the feed concentration and operating temperature and $\beta_{0}$ to $\beta_{5}$

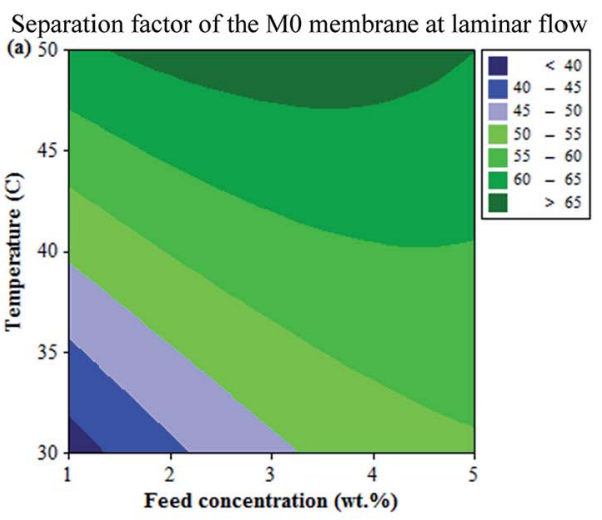

Separation factor of the M0 membrane at turbulent flow

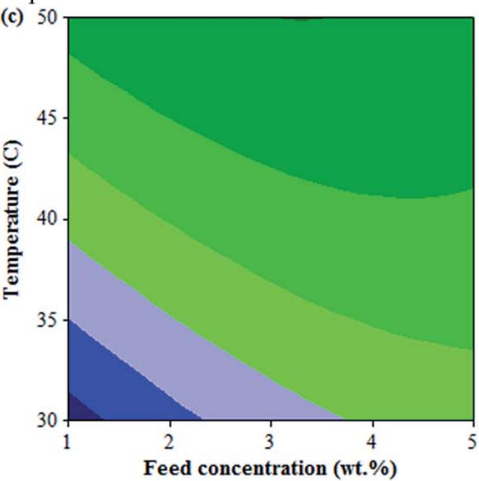

Separation factor of the M10.0 membrane at laminar flow

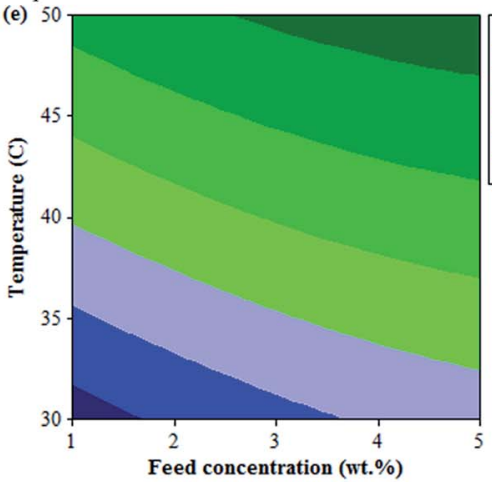

Feed concentration (wt.\%)

Separation factor of the M10.0 membrane at turbulent flow

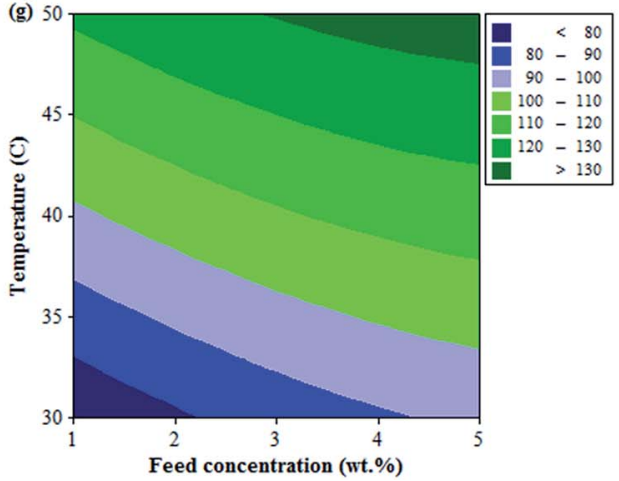

Total flux of the M0 membrane at laminar flow

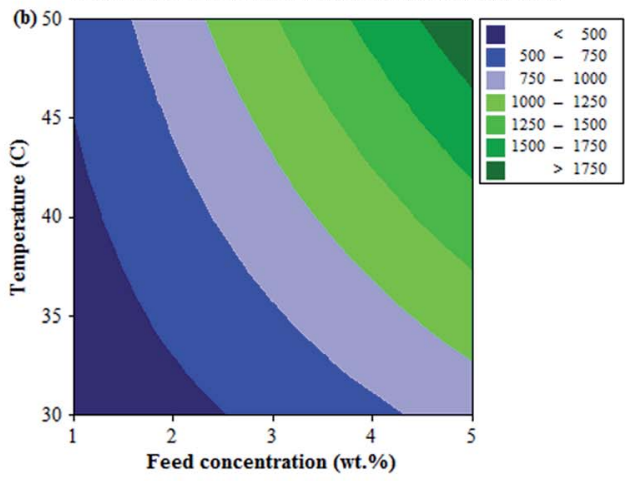

Total flux of the M0 membrane at turbulent flow

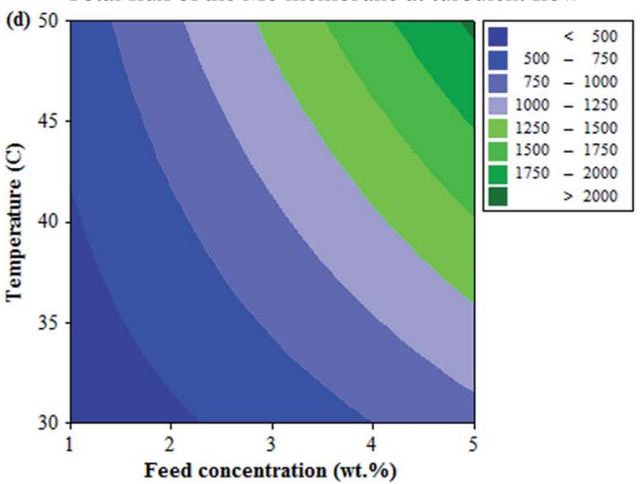

Total flux of the M10.0 membrane at laminar flow

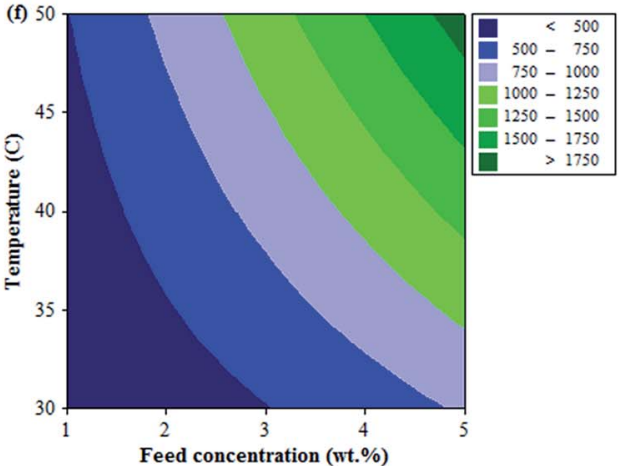

Total flux of the M10.0 membrane at turbulent flow

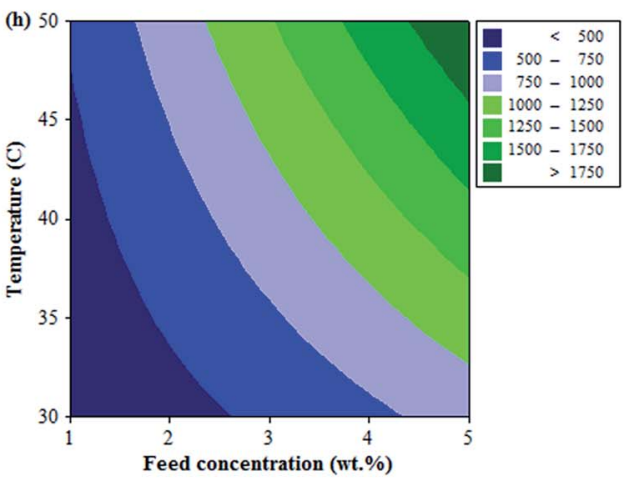

Fig. 10 The counter plots of the M0 and M10.0 membranes. 
are the constant regression coefficient of the model. All parameters of eqn (3) are reported in Table 5. As shown in Table 5 , both variables, i.e. feed concentration and temperature, had a positive effect on the separation factor and total flux of the prepared membranes at laminar and turbulent flow regimes. Moreover, the temperature had a higher effect on the separation factor compared with the feed concentration, as the $F$ value of temperature was higher than that of the EAc feed concentration. Based on the $F$ values (Tables 3 and 4 ), the singular effect of each variable was higher than the interactional effect of feed concentration and temperature. The counter plots for the measured responses as a function of feed concentration and operating temperature are illustrated in Fig. 10. The obtained results revealed that the simultaneous enhancement in the feed concentration and operating temperature resulted in increasing the separation factor and total flux of the prepared membranes. Also, the separation factor and total flux of both membranes at the turbulent flow regime were higher than the separation factor and total flux at laminar flow regime in the same condition of feed concentration and temperature. For example, by solving the statistical models and optimization of variables for $1 \mathrm{wt} \%$ EAc at a temperature of $30^{\circ} \mathrm{C}$, the separation factor and total flux of the M0 membrane were estimated to be 37.57 and $312.73 \mathrm{~g} \mathrm{~m}^{-2} \mathrm{~h}^{-1}$, respectively at the laminar flow regime and 43.15 and $335.7 \mathrm{~g} \mathrm{~m}^{-2} \mathrm{~h}^{-1}$ at the turbulent flow regime, respectively. For the M10.0 membrane at the same condition, the separation factor and total flux were estimated to be 65.88 and $270.98 \mathrm{~g} \mathrm{~m}^{-2} \mathrm{~h}^{-1}$ at the laminar flow regime, respectively and 72.10 and $294.43 \mathrm{~g} \mathrm{~m}^{-2} \mathrm{~h}^{-1}$ at turbulent flow regime respectively. The predicted values for the separation factor and total flux of membranes by models were in good agreement with the obtained experimental values.

\section{Comparison of pervaporation performance}

The pervaporation separation of EAc from aqueous solution using the prepared membranes at optimum conditions was compared with other PEBA and MMMs reported by other researchers and the results are listed in Table 6. As shown, the total flux of the

Table 6 The pervaporation performance of membranes for separation of ethyl acetate from aqueous solution

\begin{tabular}{llllll}
\hline & $\begin{array}{l}\text { Feed } \\
(\mathrm{wt} \%)\end{array}$ & $\begin{array}{l}T \\
\left({ }^{\circ} \mathrm{C}\right)\end{array}$ & $\begin{array}{l}\text { Flux } \\
\left(\mathrm{g} \mathrm{m}^{-2} \mathrm{~h}^{-1}\right)\end{array}$ & $\begin{array}{l}\text { Separation } \\
\text { factor }\end{array}$ & Ref. \\
\hline PEBA/ZSM-5 & 5 & 50 & 199.5 & 185 & 30 \\
P(VDF-HFP)/ & 5 & 45 & 737 & 123 & 54 \\
[bmim]BF4 & & & & & \\
P(VDF-HFP) & 5 & 45 & 510 & 65 & 54 \\
PDMS/PTFE & 0.99 & 30 & 276 & 95 & 55 \\
P(VDF-co-HFP) & 3 & 30 & 690 & 163 & 56 \\
P(VDF-HFP) & 3 & 30 & 415 & 80 & 57 \\
PDMS & 5 & 40 & 460 & 76 & 58 \\
PDMS/PMHS & 5 & 40 & 260 & 24 & 58 \\
Polyurethane urea & 2.5 & 30 & 250 & 655 & 59 \\
M0 & 5 & 50 & 1940 & 64.70 & This study \\
M10.0 & 5 & 50 & 1985 & 134.22 &
\end{tabular}

prepared MMMs in this work is higher than those of other reported membranes in the literature. The good balance in the trade-off between the permeation flux and the separation factor of the prepared membrane was observed. The use of ZSM-5 zeolite increased the EAc separation factor of the M10.0 membrane.

\section{Conclusion}

The EAc was successfully separated from its aqueous solution by the pervaporation process with the prepared ZSM-5/PEBA/ PES dual-layer mixed matrix membranes. The influences of zeolite content of the membrane and operating parameters of the pervaporation process like feed concentration, temperature and feed flow regime on the separation performance of the prepared membranes were investigated. The ZSM-5 zeolite nanoparticles were synthesized via the conventional hydrothermal method. The XRD pattern of ZSM-5 zeolite showed the crystalline structure of the synthesized zeolite particles. The SEM images of the prepared membranes indicated the homogenous dispersion of ZSM-5 zeolite in the top layer of the membranes up to $10 \mathrm{wt} \%$ zeolite, while the aggregation of ZSM5 nanoparticles in the top layer was observed by zeolite loading concentrations higher than $10 \mathrm{wt} \%$. The contact angle measurement indicated that the hydrophobicity and glass transient temperature of membranes was increased by loading ZSM-5 zeolite into the PEBA/PES dual-layer membranes. The maximum separation factor of 106.83 and total flux of $1298 \mathrm{~g} \mathrm{~m}^{-2} \mathrm{~h}^{-1}$ were obtained by loading $10 \mathrm{wt} \% \mathrm{ZSM}-5$ zeolite into the PEBA matrix for feed concentration of $5 \mathrm{wt} \%$ and temperature of $40{ }^{\circ} \mathrm{C}$ at laminar feed flow. The results of pervaporation experiments showed that the separation factor, total permeation flux and EAc partial flux of both neat and mixed matrix membranes were increased by increasing feed concentration from 1 to $5 \mathrm{wt} \%$ and temperature from 30 to $50{ }^{\circ} \mathrm{C}$. The water partial flux of MMMs did not change by increasing feed concentration, whereas an enhancement in the operating temperature resulted in a gradual increase in the water flux. The comparison of the membranes performance for the separation of EAc from EAc/water mixtures in the laminar and turbulent feed flow regimes revealed that the separation factor of both M0 and M10.0 membranes at the turbulent flow regime was higher than the separation factor values at the laminar flow regime. The EAc partial flux and total flux for both M0 and M10.0 membranes at the turbulent flow regime were higher than those of the laminar flow regime, whereas the water flux was almost constant at laminar and turbulent flow regimes for MMMs. The ANOVA results were evaluated for the total flux and separation factor of the M0 and M10.0 membranes as functions of feed concentration and operating temperature at laminar and turbulent flow. It was found that the temperature had a higher effect on the separation factor compared with the feed concentration, as the $F$ value of temperature was higher than that of the EAc feed concentration.

\section{Conflicts of interest}

There are no conflicts to declare. 


\section{References}

1 G. Jyoti, A. Keshav and J. Anandkumar, J. Eng., 2015, 2015, 1.

2 Y. K. Ong, G. M. Shi, N. L. Le, Y. P. Tang, J. Zuo, S. P. Nunes and T. S. Chung, Prog. Polym. Sci., 2016, 57, 1.

3 S. Tanaka, Y. Chao, S. Araki and Y. Miyake, J. Membr. Sci., 2010, 348, 383.

4 P. Sampranpiboon, R. Jiraratananon, D. Uttapap, X. Feng and R. Y. M. Huang, J. Membr. Sci., 2000, 174, 55.

5 X. Tian, B. Zhu and Y. Xu, J. Membr. Sci., 2005, 248, 109.

6 N. Ma, Z. Zhan and Z. Wang, Microporous Mesoporous Mater., 2016, 235, 100.

7 S. L. Wee, C. T. Tye and S. Bhatia, Sep. Purif. Technol., 2008, 63, 500 .

8 J. Sekulić, M. W. J. Luiten, J. E. T. Elshof, N. E. Benes and K. Keizer, Desalination, 2002, 148, 19.

9 S. D. Bhat and T. M. Aminabhavi, Sep. Purif. Rev., 2007, 36, 203.

10 C. Ding, X. Zhang, C. Li, X. Hao, Y. Wang and G. Guan, Sep. Purif. Technol., 2016, 166, 252.

11 A. Sabetghadam and T. Mohammadi, Compos. Interfaces, 2010, 17, 223.

12 C. F. Zhang, G. L. Wu, L. L. Dong, J. Tang, Y. X. Bai, Y. H. Zhu, Q. S. Liu, Y. P. Sun and J. Gu, RSC Adv., 2016, 6, 18308.

13 J. Zhao, Y. Zhu, F. Pan, G. He, C. Fang, K. Cao, R. Xing and Z. Jiang, J. Membr. Sci., 2015, 487, 162.

14 L. Aouinti, D. Roizard and M. Belbachir, Sep. Purif. Technol., 2015, 147, 51.

15 N. Wang, S. Ji, J. Li, R. Zhang and G. Zhang, J. Membr. Sci., 2014, 455, 113.

16 M. Amirilargani, M. A. Tofighy, T. Mohammadi and B. Sadatnia, Ind. Eng. Chem. Res., 2014, 53, 12819.

17 G. Dudek, M. Gnus, R. Turczyn, A. Strzelewicz and M. Krasowska, Sep. Purif. Technol., 2014, 133, 8.

18 T. Jose, S. C. George, H. J. Maria, R. Wilson and S. Thomas, Ind. Eng. Chem. Res., 2014, 53, 16820.

19 E. J. Flynn, D. A. Keane, P. M. Tabari and M. A. Morris, Sep. Purif. Technol., 2013, 118, 73.

20 M. Amirilargani and B. Sadatnia, J. Membr. Sci., 2014, 469, 1.

21 T. Khosravi, S. Mosleh, O. Bakhtiari and T. Mohammadi, Chem. Eng. Res. Des., 2012, 90, 2353.

22 H. G. Premakshi, K. Ramesh and M. Y. Kariduraganavar, Chem. Eng. Res. Des., 2015, 94, 32.

23 M. Fathizadeh, A. Aroujalian, A. Raisi and M. Fotouhi, Desalination, 2013, 314, 20.

24 Y. Fathi, A. Raisi and A. Aroujalian, Desalin. Water Treat., 2017, 60, 188.

25 S. Fazlifard, T. Mohammadi and O. Bakhtiari, Chem. Eng. Technol., 2017, 40, 648.

26 C. Zhang, L. Yang, Y. Bai, J. Gu and Y. Sun, Sep. Purif. Technol., 2012, 85, 8.

27 P. Shao and A. Kumar, J. Membr. Sci., 2009, 339, 143.

28 A. A. Kittur, S. K. Choudhari and M. Y. Kariduraganavar, Compos. Interfaces, 2006, 13, 507.

29 L. M. Vane, V. V. Namboodiri and T. C. Bowen, J. Membr. Sci., 2008, 308, 230.
30 J. Gu, X. Zhang, Y. Bai, L. Yang, C. Zhang and Y. Sun, Int. J. Polym. Sci., 2013, 2013, 1.

31 F. Asvadi, A. Raisi and A. Aroujalian, Microporous Mesoporous Mater., 2017, 251, 135.

32 S. Panahian, A. Raisi and A. Aroujalian, Desalination, 2015, $355,45$.

33 Y. Wang, Ind. Eng. Chem. Res., 2015, 54, 3082.

34 H. K. Yuan, J. Ren, X. H. Ma and Z. L. Xu, Desalination, 2011, 280, 252.

35 Y. T. Tang, Y. W. Chen, H. P. Huang, C. C. Yu, S. B. Hung and M. J. Lee, AIChE J., 2005, 51, 1683.

36 A. Penkova, G. Polotskaya and A. Toikka, Chem. Eng. Process., 2015, 87, 81 .

37 I. Sadeghi, A. Aroujalian, A. Raisi, B. Dabir and M. Fathizadeh, J. Membr. Sci., 2013, 430, 24.

38 K. Zarshenas, A. Raisi and A. Aroujalian, $R S C A d v ., 2015,5$, 19760.

39 S. A. Habibiannejad, A. Aroujalian and A. Raisi, RSC Adv., 2016, 6, 79563.

40 K. Zarshenas, A. Raisi and A. Aroujalian, J. Membr. Sci., 2016, 510, 270.

41 A. Aroujalian and A. Raisi, J. Membr. Sci., 2007, 303, 154.

42 R. Van Grieken, J. L. Sotelo, J. M. Menendez and J. A. Melero, Microporous Mesoporous Mater., 2000, 39, 135.

43 L. Shirazi, E. Jamshidi and M. R. Ghasemi, Cryst. Res. Technol., 2008, 43, 1300.

44 B. Yu, H. Cong, Z. Li, J. Tang and X. S. Zhao, J. Appl. Polym. Sci., 2013, 130, 2867.

45 M. M. Rahman, V. Filiz, S. Shishatskiy, C. Abetz, S. Neumann, S. Bolmer, M. M. Khan and V. Abetz, J. Membr. Sci., 2013, 437, 286.

46 J. H. Kim, B. R. Min, J. Won, S. H. Joo, H. S. Kim and Y. S. Kang, Macromolecules, 2003, 36, 6183.

47 X. Qiao, T. S. Chung and R. Rajagopalan, Chem. Eng. Sci., 2006, 61, 6816.

48 A. Raisi, A. Aroujalian and T. Kaghazchi, Sep. Sci. Technol., 2009, 44, 3538.

49 M. Peng, L. M. Vane and S. X. Liu, J. Hazard. Mater., 2013, 98, 69.

50 B. K. Dutta and S. K. Sikdar, Environ. Sci. Technol., 1999, 33, 1709.

51 R. Psaume, P. Aptel, Y. Aurelle, J. C. Mora and J. L. Bersillon, J. Membr. Sci., 1988, 36, 373.

52 L. Li, Z. Xiao, S. Tan, L. Pu and Z. Zhang, J. Membr. Sci., 2004, 243, 177.

53 H. Tan, Y. Wu and T. Li, J. Appl. Polym. Sci., 2013, 129, 105. 54 D. Yongquan, W. Ming, C. Lin and L. Mingjun, Desalination, 2012, 295, 53.

55 W. D. Zhang, W. Sun, J. Yang and Z. Q. Ren, Appl. Biochem. Biotechnol., 2010, 160, 156.

56 B. K. Zhu, X. Z. Tian and Y. Y. Xu, Desalination, 2005, 184, 71. 57 X. Tian, X. Jiang, B. Zhu and Y. Xu, J. Membr. Sci., 2006, 279, 479.

58 M. Osorio-Galindo, A. Iborra-Clar, I. Alcaina-Miranda and A. Ribes-Greus, J. Appl. Polym. Sci., 2001, 81, 546.

59 Y. Bai, J. Qian, C. Zhang, L. Zhang, Q. An and H. Chen, J. Membr. Sci., 2008, 325, 932. 